\title{
Measuring perceived morphological relatedness
}

\author{
KATHLEEN CURRIE HALL, CLAIRE ALLEN, TESS FAIRBURN, MICHAEL FRY, \\ MICHAEL MCAULIFFE and KEVIN MCMULLIN
}

kathleen.hall@ubc.ca

\begin{abstract}
This paper provides a metric for determining whether a given pair of English words is perceived to be morphologically related, based on objective measurements of the words' orthographic, phonetic, and semantic similarity to each other. The metric is developed on the basis of results from a behavioural study in which participants were asked to judge the relative similarity of pairs of words. The metric is intended to help researchers determine which forms in a language plausibly have segments that alternate; as an example, it is applied to the lexicon of English to illustrate its utility in calculating the frequency of alternation of [s] and [J].
\end{abstract}

Keywords: morphology, similarity, perception, alternation, modeling

\section{Résumé}

Cet article propose une méthode pour déterminer si deux mots anglais sont perçus comme étant morphologiquement reliés. Cette méthode est fondée sur des mesures objectives, comme des similitudes orthographiques, phonétiques et sémantiques. L'approche est issue des résultats d'une étude behaviorale où les participants ont jugé la similitude relative d'une paire de mots. Cette méthode a pour but d'aider les chercheurs à déterminer quelles formes dans une langue donnée ont plausiblement des segments qui alternent ; comme exemple, nous appliquons la méthode au lexique de l'anglais pour illustrer son utilité dans le calcul de la fréquence de l'alternance de [s] et [J].

Mots-clés: morphologie, similitude, perception, alternance, modèle

\section{INTRODUCTION}

The purpose of this paper is to develop a metric of morphological relatedness that reflects the perceptions of relatively naïve speakers, as determined by a behavioural study. Morphological structure has long been known to have an influence on both lexical processing and production (e.g., Forster and Chambers 1973, Murrell and Morton 1974, Taft and Forster 1975, Burani and Caramazza 1987, Napps and Fowler 1987, Napps 1989, Marslen-Wilson et al. 1994, Baayen et al. 1997, 
Radeau et al. 1998, Meunier and Segui 1999, Feldman 2000, Frost et al. 2000, Hay 2003, Moscoso del Prado Martín 2003, Morris et al. 2007, Longtin et al. 2003, Pluymaekers et al. 2005, Stockall and Marantz 2006, Gonnerman et al. 2007, Baayen et al. 2008, Pastizzo and Feldman 2009, Tabak et al. 2010, Bien et al. 2011, Smolka et al. 2014, Xu and Taft 2015, inter alia). For example, morphologically related words have been shown to prime each other in ways that are different from sound-based and meaning-based priming (e.g., Murrell and Morton 1974, Napps and Fowler 1987, Napps 1989, Marslen-Wilson et al. 1994, Feldman 2000, Frost et al. 2000, Smolka et al. 2014; see especially the review in Feldman 2000), and the frequency of occurrence of morphological roots within derived words affects the speed of processing (e.g., Taft and Forster 1975, Burani et al. 1987, Meunier and Segui 1999, Xu and Taft 2015). At the same time, less work has been done on how one can determine whether any two words are perceived by native speakers to be morphologically related; instead, such studies rely on $a$ priori notions of morphological relatedness. Yet this perceived relation has consequences for a number of areas of linguistic analysis.

In phonology, for example, one of the primary phenomena to be explained is the existence of alternations: why does one sound occur in some environments, but a phonetically different sound regularly occur in other environments? In order for this to be a sensible question, however, one must be able to recognize the recurrence of morphemes from one context to another, specifically when they are not identical in form across contexts. Without recognition that a morpheme is the "same" in two or more contexts, there is no sense in which sounds alternate with each other. For example, the $[\mathrm{k}]$ at the beginning of couch does not alternate with the $[\mathrm{s}]$ at the beginning of sofa, even if they occur in word-initial positions of two words that mean roughly the same thing; similarly, the [k] and [s] in cat and sat do not alternate with each other despite their shared phonological environment. The $[\mathrm{k}]$ and $[\mathrm{s}]$ in electri $[\mathrm{k}]$ vs. electri[s]ity, however, do show an alternation, but only if we assume that it is the same morpheme, electric-, that occurs in both words.

Linguists tend to use meta-linguistic knowledge to organize data into morphologically related datasets (e.g., base forms and their plurals, negatives, diminutives, etc.). The assumption is that naïve language users can and do make similar classifications, but it is not clear how accurate this assumption is. For example, Johnson and Babel (2010) directly compare the phonological status of [s] and [J] in Dutch and English. In Dutch, the two sounds are often thought to be allophonic (e.g., Booij 1995, Gussenhoven 1999), given alternations between singular forms and their diminutives such as tas [tas] 'bag' $\sim$ tasje [tafə] 'handbag,' ijs [Eis] 'ice' $\sim$ ijsje [عifə] 'ice cream,' and glas [xlas] 'glass' glasje [xlajə] 'small glass, lens.' In English, however, the sounds are typically assumed to be contrastive, given (near) minimal pairs such as sue vs. shoe, seesaw vs. seashore, or mass vs. mash. As Johnson and Babel (2010) point out, however, [s] and []] do undergo morphophonological alternation in English, as in opress $\sim$ oppression, press $\sim$ pressure, or face $\sim$ facial, but they dismiss the relevance of this, saying that "alternations of this type are infrequent in English and the phonemic contrast between $/ \mathrm{s} /$ and $/ \mathrm{J} /$ is a very salient aspect of the English phonological system" (Johnson and Babel 2010: 129; emphasis 
added). Interestingly, parallel to the existence of alternations in addition to contrasts in English, there is in fact some evidence of surface contrast between [s] and [S] in Dutch, in addition to their regular alternations: there are words like tassen [tasə(n)] 'bags' that have [s] before [ə] and therefore form a surface minimal pair with words like tasje [tafə] 'handbag.' in terms of the degree of the contrast, rather than its quality: Johnson and Babel seem to be arguing that the ratio of minimal pairs to alternations is much higher in English than in Dutch, and then go on to show that this difference has consequences for the perception of these fricatives in the two languages.

In order to evaluate this claim, however, there needs to be a way of quantifying the frequency with which two sounds alternate. One way of determining the frequency of the alternation would be to calculate the number of words that contain morphemes that have both [s]- and [J]-ful allomorphs and compare that to the number of words that contain morphemes that have allomorphs that consistently contain only one of [s] or [f]. To do this, however, one must have a good sense of what should "count" as containing an allomorph of a given morpheme. For example, does the root morpheme face occur in the word face? in face-lift? facial? type-face? facet? façade? superficial? Etymologically speaking, the answer to each of these is yes, but it is much less clear that naïve English speakers recognize this connection in all of these (and other) cases. (Note that the same problem arises in Dutch: the diminutive suffix in Dutch is generally considered to be derivational, not inflectional (Bauer 1997, ten Hacken 2013), as the somewhat semantically opaque nature of meisje 'girl' - for which there is no base form - suggests.)

Thus, even though the perceived morphological relations between words are not always clear, the implicit assumption that morphological structure reveals phonological patterns is present in countless examples of phonological analysis. Some phonologists (e.g., Silverman 2006: 88, see also Lu 2012) have even made the claim that alternations are the only way to identify allophonic phonological patterns, discounting other common criteria such as complementarity of distribution (Silverman 2006: 101-106) and phonetic similarity (Silverman 2006: 95-100).

Thus, there is a need for an objective metric of perceived morphological relatedness that can be applied to word pairs to determine whether they are likely to be thought of as being morphologically related and therefore a candidate for alternation. The purpose of this paper is to establish a methodology for doing exactly that and apply it to a particular language; in this case, English. In section 2, prior work on measuring morphological relatedness is discussed, and rationale for the current task is given. Sections 3 and 4 present the design and results of the behavioural study. In section 5, the analysis of these results is turned into a predictive metric of perceived morphological relatedness and the results are tested with novel words. Section 6 presents conclusions.

\footnotetext{
${ }^{1}$ Note that word-final [n] is generally considered optional in Dutch.
} 


\section{MEASURING MORPHOLOGICAL RELATEDNESS}

As mentioned in the introduction, the role of morphology has been extensively examined in the psycholinguistic literature. As a number of authors (e.g., Gonnerman et al. 2007, Smolka et al. 2014) have pointed out, much of the work in this area has been focused on whether complex words are stored and processed as decomposed parts or as non-decomposed wholes, with another sub-branch of research on how to analyse words whose morphological structure is not entirely clear (e.g., grocer, remit, cranberry; see, for example, Aronoff 1976).

Of most direct relevance to the current question are studies that have investigated the existence of morphological relatedness, often through its indirect effect on priming in tasks such as lexical decision (e.g., Marslen-Wilson et al. 1994, Radeau et al. 1998, Feldman 2000, Frost et al. 2000, Longtin et al. 2003, Stockall and Marantz 2006, Gonnerman et al. 2007, Pastizzo and Feldman 2009, Smolka et al. 2014 , etc.). Morphologically related words have been shown to induce facilitatory effects that go beyond phonological and semantic similarity, though there is variability in the results such that the extent to which morphology is separate from the combined effects of other forms of similarity is still in doubt (see especially the discussion in Longtin et al. 2003, Stockall and Marantz 2006, Pastizzo and Feldman 2009, and Smolka et al. 2014). Generally speaking, though, such studies involve carefully controlled stimuli in which words are quite clearly either morphologically related or unrelated. Feldman (2000), for example, seems to use "morphologically related" to mean "inflectionally related", and even studies that examine derivational relations generally have very strict criteria for determining that two words can be considered to be morphologically related. Marslen-Wilson et al. (1994) used the criteria shown in (1); they considered pairs of words to be either morphologically related or not, without any intermediate categories.

(1) Criteria for morphologically related stimuli in Marslen-Wilson et al. (1994: 7)

a. The derived form has a "recognizable" affix (determined by listing in one of two standard references);

b. The stem without its affix has the same form (at least underlyingly) as the stem that occurs as a free word;

c. The pair of words have a common etymological source.

These criteria quite clearly delimit sets of words that can be considered to be morphologically related, and are entirely reasonable for the kind of question under study in that paper, that is, whether morphological relatedness affects priming. It is not so clear, however, that native speakers would have the same judgements; for example, the criteria count all of friend $\sim$ friendly, elude $\sim$ elusive, and grade $\sim$ gradual as being morphologically related. This may in fact be entirely accurate, but the key points are (a) that the morphological status is pre-determined in these studies, (b) that such determinations are binary, and (c) that the results of such studies are interpreted as reflecting the morphological status, rather than themselves being used to examine perceived morphological relatedness itself. Note in particular 
that Marslen-Wilson et al. explicitly excluded "pairs that had coincidentally homophonic stems" (7) that otherwise met their first two criteria, thus prioritizing historical relatedness over potential perceived relatedness, whether that perception is historically accurate or not. Longtin et al. (2003), however, found effects similar to the priming effects in Marslen-Wilson et al. (1994), even with "pseudo-derived" words, i.e., words that look as though they could be morphologically related even if they are not etymologically related, such as artery-art. This finding suggests that perceived morphological relatedness may indeed be different from historical relatedness.

Several more recent studies directly address point (b), that is, whether relatedness is binary or gradient (e.g., Feldman et al. 2004, Gonnerman et al. 2007, Morris et al. 2007, Xu and Taft 2015). Gonnerman et al. (2007), for example, do a series of pre-tests for phonological and semantic relatedness, using a Likert scale to gather judgements of similarity of each type. They then divide their stimuli into low-, medium-, and high-similarity groups along each of these domains, and control for the other: for example, in their experiment 1 , they hold phonological similarity constant while using gradient degrees of semantic similarity; in their experiment 2, the factors are reversed. They find that degrees of similarity do affect priming: for example, they find twice as much priming for highly semantically similar pairs as for pairs with a medium degree of semantic similarity, and again about twice as much for pairs that were different only in terms of a consonant change as compared to both a consonant and vowel change in the root morpheme, although it should be noted that this effect was found only for words that were already highly semantically similar. Furthermore, they argue that, given these gradient results, "effects of morphological structure on processing should be predictable from the degree of semantic and phonological overlap between words" rather than constituting an independent level of processing (Gonnerman et al. 2007: 338). They propose that this can best be captured by a distributed connectionist model, in which morphology emerges from phonological and semantic representations.

The behavioural study presented here builds on Gonnerman et al. (2007) and is designed to test a wider range of semantic and phonological similarity. It also incorporates measures of orthographic similarity, as other prior studies have indicated that spelling can also play a role in the perceived structure of words (e.g., Carlisle 1988, Feldman 2000; see also discussion and review in Baayen 2014). Indeed, Carlisle (1988: 154) claims that "the morphemic structure of words [...] may be more apparent from the orthography than the phonology".

Additionally, the current study deviates from most studies in morphological processing in that it involves a meta-linguistic judgement rather than a measure of an implicit response: participants were directly asked to judge the similarity of pairs of words (see section 3 for details), rather than perform some unrelated task in which reaction time is used to measure the extent to which different pairs of words prime each other. This method was chosen partially to serve as a comparison to the welldocumented effects of priming, and partially because priming effects have in fact not been found in certain conditions. For example, Marslen-Wilson et al. (1994) found that morphologically related words did not prime unless they were also 
semantically related (as an example of a morphologically but not semantically related pair, consider casual casualty: according to their criteria, these are morphologically related, but were not judged to be semantically related in a pre-test of native speakers). They also found that phonologically related words that are not morphologically or semantically related did not reliably prime. Feldman (2000) found that orthographically related primes can either inhibit or facilitate targets in a lexical decision task, depending on the latency between the two. Thus, we were wary of using a priming task. By contrast, similarity rating has been used successfully in several studies to determine independent degrees of phonological and semantic similarity (Feldman et al. 2004, Morris et al. 2007, Gonnerman et al. 2007, Boomershine et al. 2008, Xu and Taft 2015). We were thus more confident that asking about similarity would yield results in all cases. That is, by using a similarity comparison task, we hoped to ensure that all comparison types (morphological, semantic, and phonological) would be represented in the resulting similarity continuum, and specifically that both form and meaning similarity would be recognizable as such. That said, the task certainly allowed participants to make metalinguistic, conscious judgements about similarity that would have been minimized in a priming task.

\section{EXPERIMENT DESIGN}

The basic design of the experiment was to use an AXB comparison task, where participants saw a key word and were asked which of two comparison words was more similar to that key word. For example, on a single trial, the key word might be press, and the two comparison words might be pressure and expressway, or expressway and dress, etc. Participants simply had to indicate which of the two comparison words was, according to their subjective judgement, more similar to the key. Note that this differs from a more standard similarity rating task, where there are at least implicit comparisons across trials in addition to within trials about how similar a given trial pair is in comparison to other trial pairs in the experiment. This method makes it easier to compare results across participants, who might otherwise be using very different interpretations of a similarity rating scale, and likely also makes it easier for participants, who can focus on a single trial at a time.

The rationale for this experimental design was that participants would likely have three basic criteria on which to make similarity judgements: (a) semantic relatedness, (b) phonological relatedness, and (c) orthographic relatedness. Words that are morphologically related should be seen to share both semantic and phonological relatedness (and quite likely orthographic relatedness), and should therefore be reliably chosen as more similar than non-morphologically related words. If naïve language users do not perceive any morphological relatedness between a pair of words, then they should treat them as no different from other words that happen to share some semantic, phonological, or orthographic similarity. For example, if speakers do not perceive the admittedly distant morphological relation between press and expressway, they would be expected to choose relatively randomly between expressway or dress, both of which share phonological and orthographic 
similarity to press: the former contains the whole string <press> within it, while the latter contains only $<$ ress $>$, but matches in terms of syllable count and rhyme. On the other hand, if they perceive the morphological relation, then they should pick expressway consistently over dress. By doing all possible comparisons of semantically related, phonologically related, morphologically related, and unrelated words, participants are forced to make judgements about different kinds of similarity and to indicate the relative importance they assign to semantic, phonological, and orthographic relatedness. Note that this is not a direct measure of morphological relatedness or even of perceived morphological relatedness; we simply assume that there should be a correlation between perceived similarity and perceived morphological relatedness, and exploit this correlation to create a metric. ${ }^{2}$ As mentioned above, this framework is similar to the approach taken in distributed connectionist models (e.g., Seidenberg and McClelland 1989, Seidenberg and Gonnerman 2000, Gonnerman et al. 2007) and naïve discriminant learning models (Baayen et al. 2011), in that morphological structure is assumed to be an emergent effect of the interactions between form and meaning similarity (see discussion in e.g., Baayen 2014, though some evidence against such a view is found in Stockall and Marantz 2006).

\subsection{Stimuli}

The stimuli consisted of 180 unique key words and a set of nine comparison words for each one; these are all listed in the Appendix. The nine comparison words consisted of: an inflected form; two derived forms, one of which was intended to be more transparent than the other, as discussed below; two words that were semantically related to the key without being etymologically related; two words that were phonologically related to the key without being etymologically related; and two words that were unrelated to the key.

Key words were selected by three native English speakers brainstorming words that were likely to have comparison words of the right kinds. The selection process for comparison words was as follows. The inflected form was chosen by doing a Google ngram search for inflected forms of the key; the most frequent inflected form was picked. The first, more transparent derivationally related form had only one affix in addition to the key, and ideally was listed in WordNet (Princeton 2010) as a derivationally related form; if no such word was available, a word that was felt to be relatively transparent was chosen and verified by two native English speakers. The second, ostensibly less transparent derivationally related form generally had two affixes attached to the key word and was found by a search in an online etymological dictionary, to verify that it was historically related to the key. Thus, the primary difference in transparency was due to the number of affixes, but was also confirmed by the intuitions of two native speakers. The two semantically related

\footnotetext{
${ }^{2}$ See also Pastizzo and Feldman (2009), who find similar priming effects in words that are related in form and meaning but not morphologically related, such as boat-float, as they do in words that are morphologically related.
} 


\begin{tabular}{lll}
\hline \hline Key: & PRESS & RIGHT \\
\hline Inflected & pressed & rights \\
Derived 1 & pressure & rightful \\
Derived 2 & expressway & righteousness \\
Meaning 1 & push & entitlement \\
Meaning 2 & media & correct \\
Rhyme & mess & flight \\
Cohort & preppy & rhyme \\
Unrelated 1 & table & apple \\
Unrelated 2 & sofa & orange \\
\hline \hline
\end{tabular}

Table 1: Example stimuli

forms were picked using the most frequently attested conventional meanings (senses) in WordNet for the key; the primary meaning was chosen from the definition of the most frequent sense, and the secondary meaning from the definition of the most frequent sense that belonged to a different lexical category than the primary sense, if available, and otherwise from the definition of the second most frequent sense overall. The first phonologically related form was a rhyming form, which, wherever possible, matched the key word from its stressed vowel to the end of the word, and otherwise came as close to such a match as possible (as judged by two native speakers of English). The second phonologically related form was a cohort-sharing form, which, wherever possible, shared all material from the beginning of the word through to the stressed vowel (inclusive), and again came as close to that ideal as possible if there was no exact match. The two unrelated words were chosen essentially at random, trying to avoid any obvious ways in which they could be semantically related to the key. They never shared an initial phoneme with the key, nor did they ever rhyme with the key. The two unrelated words were also matched to each other in terms of syllable count and lexical category, to avoid one of the two being more similar in either of these ways than the other to the key word (this is necessary for times when the two unrelated words are paired with each other). ${ }^{3}$ Examples are given in Table 1; the complete set of 1,620 comparison words is available in the Appendix. It should be noted that trying to find words in a natural language that entirely meet the guidelines laid out above is nearly impossible; it is our hope that having as many key words as we do (180) will allow generalizations about comparison types to emerge even though not every instance of a comparison word is an ideal match to the goal.

\footnotetext{
${ }^{3}$ Note that given the wide variety of other words, it would not be possible to match the unrelated words in terms of lexical category, number of syllables, etc., to any of the other categories being tested; nor would we have wanted there to be a consistent match between the unrelated words and one particular other category of comparison words.
} 
HIGH

hike

sigh

Press ' 1 ' if the middle word seems more like the word on the left. Press ' 5 ' if the middle word seems more like the word on the right.

Figure 1: Example of an E-Prime trial

All nine comparison words were paired with every other comparison word for a given key, for 36 types of comparison pair $(8+7+6+5+4+3+2+1=36$ pairs $)$ and put in both possible orders, for a total of 72 possible pairs $(36 * 2=72)$ for each of the 180 key words. There were thus 12,960 total unique triples of key word and comparison pair $(72 * 180=12,960)$. To ensure that individual participants saw any given key word no more than twice, these triplets were divided into 36 groups of 360 triplets each, with two triplets per key word. The triplets were randomly selected for each group, with the caveat that no group contained two triplets that were identical except for the order of the comparison words. Thus, while every group ended up with a random sample of the triplets, the precise number of comparison types that any group had were not the same. For example, one group might have seen five examples of an inflected-unrelated comparison, while another saw only three.

\subsection{Procedure}

Participants were seated at individual PC workstations with sound-absorbing partitions. Up to four participants were run simultaneously. After a set of four practice trials, participants proceeded to the 360 test trials. An opportunity to take a break was provided after each set of 80 test trials. On any given trial, a key word was presented at the top of the screen in capital letters, with the two comparison words for that trial presented in lowercase letters below the key, to the left and right, as shown in Figure 1. Participants were instructed to press " 1 " on an accompanying button box if they thought the word on the left was more similar to the key word, and press " 5 " if they thought the word on the right was more similar. No information about how similarity should be determined was given; if a participant asked for clarification, they were told that they were free to use their own judgements. Instructions were shown on screen below every triplet. Although reaction time was recorded, there was no time limit on the trials, and participants were not given any guidelines about how long they should take. The time to complete a session varied widely across participants, from approximately 15 minutes to approximately 50 minutes; most participants completed the task in approximately 30 minutes.

Each participant was randomly assigned to one of the 36 groups using the psychological testing software E-Prime (Psychology Software Tools 2012), and the 360 stimuli for that group were presented in random order for each participant in that group, also using E-Prime. 


\subsection{Participants}

Five English-speaking participants completed each of the 36 groups, for a total of 180 participants. ${ }^{4}$ All participants self-rated their English proficiency as a 7 on a scale of 1-7 on a post-experiment questionnaire. ${ }^{5}$ Participants were recruited through the University of British Columbia community and received either $\$ 10$ or course credit for participation. Note that the participants were for the most part undergraduate students at the university and therefore were expected to have a relatively high degree of morphological awareness given their age and education levels (Sternberg and Powell 1983, Tyler and Nagy 1989).

\section{RESUlts}

For each of the nine different comparison word types (inflection, derived-1, derived-2, meaning-1, meaning-2, rhyme, cohort, unrelated-1, unrelated-2), a first way to examine the data is to calculate the percentage of the time that that type was chosen, relative to all the trials in which that type was an option. Because all options were presented equally often, the null hypothesis would be that any given type would be selected in $50 \%$ of the trials where it was an option, with all other types sharing equally in the other $50 \%$ of the trials (i.e., $50 \%$ / $8=6.25 \%$ each). Larger percentages indicate a tendency for that type to be chosen over the other words it was paired with; smaller percentages indicate a tendency for other choices to be selected instead. Table 2 shows the percentage of the time that each type was chosen, relative to the set of trials where it was an option. Rows represent all trials in which a certain type was an option. Columns show which type was actually chosen in any given trial that contained the option indicated by the row. Row totals therefore sum to $100 \%$; column totals are meaningless. For example, when an inflected form was one of the two choices given, it was selected $83.3 \%$ of the time, while a transparent derived form was selected $4.1 \%$ of the time. On the other hand, when a transparent derived form was one of the two choices given, it was chosen $75.1 \%$ of the time, and an inflected form was chosen $8.4 \%$ of the time. ${ }^{6}$

\footnotetext{
${ }^{4}$ In fact, many additional participants actually took part as part of their course credits; a random sample of those who self-rated at the top level of English proficiency were selected for analysis, giving five top-rated English speakers in each stimulus group.

${ }^{5}$ Note that the question of being a "native" English speaker is a particularly difficult one for many students at UBC (and other universities in areas of high immigration) to answer. Many students were born and raised in Vancouver, but spoke a language other than English at home until the age of 4 or 5. These are highly proficient, native-sounding English speakers whose first language does not happen to be English, many but not all of whom would self-identify as a native English speaker. Thus, we use self-rated proficiency as our metric rather than the more nebulous notion of "nativeness."

${ }^{6}$ Note that the numbers for head-to-head trials between inflected and derived-1 forms are different in the two rows because the comparison set is different. That is, in row 1 , we see that a derived-1 form was chosen on $4.1 \%$ of all the trials that an inflected form was an option; in row 2, we see that an inflected form was chosen on $8.4 \%$ of all the trials when a
} 


\begin{tabular}{|c|c|c|c|c|c|c|c|c|c|c|}
\hline & & \multicolumn{9}{|c|}{ What was selected } \\
\hline & & Inflected & Derived 1 & Derived 2 & Meaning 1 & Meaning 2 & Rhyme & Cohort & Unrelated 1 & Unrelated 2 \\
\hline \multirow{9}{*}{$\begin{array}{l}\text { All trials } \\
\text { where__was an } \\
\text { option }\end{array}$} & Inflected & 0.833 & 0.041 & 0.025 & 0.039 & 0.029 & 0.018 & 0.007 & 0.004 & 0.004 \\
\hline & Derived1 & 0.084 & 0.750 & 0.035 & 0.045 & 0.035 & 0.026 & 0.014 & 0.005 & 0.006 \\
\hline & Derived2 & 0.100 & 0.090 & 0.622 & 0.060 & 0.048 & 0.037 & 0.026 & 0.009 & 0.009 \\
\hline & Meaning1 & 0.086 & 0.080 & 0.065 & 0.616 & 0.049 & 0.045 & 0.036 & 0.011 & 0.012 \\
\hline & Meaning2 & 0.096 & 0.090 & 0.077 & 0.076 & 0.529 & 0.056 & 0.045 & 0.016 & 0.014 \\
\hline & Rhyme & 0.107 & 0.099 & 0.088 & 0.080 & 0.069 & 0.476 & 0.044 & 0.019 & 0.019 \\
\hline & Cohort & 0.118 & 0.111 & 0.099 & 0.089 & 0.080 & 0.081 & 0.369 & 0.026 & 0.027 \\
\hline & Unrelated1 & 0.121 & 0.120 & 0.116 & 0.114 & 0.109 & 0.106 & 0.099 & 0.154 & 0.060 \\
\hline & Unrelated2 & 0.121 & 0.119 & 0.116 & 0.113 & 0.111 & 0.106 & 0.098 & 0.065 & 0.151 \\
\hline
\end{tabular}

Table 2: Percentage of the time that each word type was picked, relative to the total set of times that type was an option. For example, the first row shows what word type was picked for all the trials in which inflected forms were an option. Row totals therefore sum to 1 . Chance would have all cells on the diagonal at 0.50 and all other cells in any given row at 0.0625 . 
Note that at chance, the entries along the diagonal would all be 0.50 , and all other cells would be $0.50 / 8=0.0625$. That is, each of the other eight choices would also have been selected with equal probability when a given option was a choice. Thus, in the examples above, the inflected and transparent derived forms were each chosen more often than expected by chance, looking across all their comparison types $(83.3 \%>50 \%, 75.1 \%>50 \%)$. When a transparent derived form was paired with an inflected form, however, the transparent derived form was picked less often than expected by chance $(4.1 \%<6.25 \%)$, and the inflected form was picked more often than expected by chance $(8.4 \%>6.25 \%)$.

The first observation to make is that the percentages with which each comparison type was chosen line up extremely well with the intended similarity. That is, inflected forms were chosen most often (chosen $83 \%$ of the time that they were available), followed by transparent derived forms $(75 \%)$, then opaque derived forms and primary meaning forms $(62 \%$ each), secondary meaning forms $(53 \%)$, rhymes $(48 \%)$, cohorts $(37 \%)$, and finally unrelated forms $(15 \%)$.

A linear regression to predict the percentage of time any given individual word was chosen based on what type of word it was (e.g., the percentage of time pressure was chosen, given that it's a derived-1 word) was statistically significant, with $\mathrm{p}<0.001$. Each of the nine word types was each individually significant, also with $\mathrm{p}<0.001$ for each. The adjusted $\mathrm{R}^{2}$ of the model is 0.86 . See Table 3 for details. ${ }^{7}$

Post-hoc pairwise comparisons on the individual types (shown in the final column of Table 3) showed that each type was statistically significantly different from the one immediately below it on the list (i.e., inflected vs. derived-1, derived1 vs. derived-2, etc.), each with p-values of less than 0.001 , with two exceptions: derived-2 forms were not significantly different from meaning-1 forms, and the two unrelated forms were not significantly different from each other.

Note that, although meaning-2 forms and rhymes were each chosen with percentages close to $50 \%$ in Table 2 , this does not mean that they were being chosen randomly. They would be at chance only if all other elements in the rows were also at chance, that is, at $6.25 \%$. Instead, every element that occurs to the left of the diagonal (in every row, including those for meaning-2 forms and rhymes) is greater than $6.25 \%$, while every element that occurs to the right of the diagonal in every row is less than $6.25 \%$. Thus, elements at the beginning of the list are all occurring more often

derived-1 form was an option. To put this another way that shows the more direct comparison: in row 1, inflected forms were always an option, but derived-1 forms were not. Of all the trials when inflected forms and derived forms were actually pitted against each other, which is $12.5 \%$ of the total trials where inflected forms were an option, derived- 1 forms were selected $4.1 \%$ of the time; $4.1 / 12.5=32.8 \%$. In row 2 , derived- 1 forms were always an option. In $12.5 \%$ of these trials, inflected forms were an option, and of these, $8.4 \%$ were cases where the inflected form was chosen; $8.4 / 12.5=67.2 \%$. So, on the head-to-head trials between inflected and derived- 1 forms, inflected forms were chosen $67.2 \%$ of the time and derived- 1 forms were chosen $32.8 \%$ of the time.

${ }^{7}$ Inflected forms were chosen as the intercept simply to keep the model in the same order as the predicted (and found) results (e.g., those shown in Table 2); the overall results are identical if an unrelated form is taken to be the intercept. 


\begin{tabular}{|c|c|c|c|c|c|}
\hline & Coefficient & $\begin{array}{l}\text { Standard } \\
\text { Error }\end{array}$ & t-value & p-value & $\begin{array}{l}\text { t-test with } \\
\text { following entry }\end{array}$ \\
\hline $\begin{array}{l}\text { Intercept } \\
\text { (Inflected) }\end{array}$ & 0.833 & 0.007 & 120.093 & $<0.001$ & $\begin{array}{l}\mathrm{t}(320.69)=10.49 \\
\mathrm{p}<0.001\end{array}$ \\
\hline Derived-1 & -0.083 & 0.010 & -8.465 & $<0.001$ & $\begin{array}{l}\mathrm{t}(358)=13.07 \\
\mathrm{p}<0.001\end{array}$ \\
\hline Derived-2 & -0.211 & 0.010 & -21.523 & $<0.001$ & $\begin{array}{l}t(347.54)=0.504 \\
p=0.61(N S)\end{array}$ \\
\hline Meaning-1 & -0.217 & 0.010 & -21.111 & $<0.001$ & $\begin{array}{l}\mathrm{t}(358)=6.95 \\
\mathrm{p}<0.001\end{array}$ \\
\hline Meaning-2 & -0.304 & 0.010 & -31.008 & $<0.001$ & $\begin{array}{l}\mathrm{t}(347.15)=4.52 \\
\mathrm{p}<0.001\end{array}$ \\
\hline Rhyme & -0.357 & 0.010 & -36.415 & $<0.001$ & $\begin{array}{l}\mathrm{t}(358)=10.52 \\
\mathrm{p}<0.001\end{array}$ \\
\hline Cohort & -0.461 & 0.010 & -47.329 & $<0.001$ & $\begin{array}{l}\mathrm{t}(286.75)=27.83 \\
\mathrm{p}<0.001\end{array}$ \\
\hline Unrelated-1 & -0.679 & 0.010 & -69.242 & $<0.001$ & $\begin{array}{c}\mathrm{t}(358)=-0.394 \\
\mathrm{p}=0.69(\mathrm{NS})\end{array}$ \\
\hline Unrelated-2 & -0.682 & 0.010 & -69.539 & $<0.001$ & NA \\
\hline \multicolumn{6}{|c|}{$\begin{array}{r}\mathrm{F}(\mathrm{8} / \mathrm{1611})=1201 ; \mathrm{p}<0.001 \\
\text { Adjusted } \mathrm{R}^{2}=0.86\end{array}$} \\
\hline
\end{tabular}

Table 3: Details of a linear regression model, predicting percentage of each word type chosen, from word type. The final column shows the results of a post-hoc t-test comparing the given entry's percentage with the following entry's percentage.

than expected by chance as compared to elements at the end of the list. Ones that end up being selected close to $50 \%$ of the time are being actively selected that often, that is, less often than elements to their left and more often than elements to their right, which happens in these cases to average out to $50 \%$, but does not actually indicate random selection.

These results provide strong evidence that the categories assumed by linguists are, by and large, psychologically real in how they relate words to each other, at least insofar as perceived similarity can be used as a measure of relatedness. Morphologically related forms (inflected and derived forms) are the most similar to root forms. Semantically related forms are next, with primary meanings being more closely associated with the root than secondary meanings. Phonologically related forms are next, with rhymes being considered more similar than cohorts. All of the preceding relations are considered to be more similar to root words than unrelated forms. These results line up with prior findings; for example, Radeau et al. (1998) similarly found that semantic relations caused more priming (measured using reaction time) and less surprisal (measured using event-related potentials) than phonological relations. It has also been found that rhymes cause more priming than cohorts (see discussion in Radeau et al. 1998). In spoken word processing, of course, cohorts are more highly activated than rhymes (e.g., Marslen-Wilson and 
Zwitserlood 1989, Allopenna et al. 1998), but this could very well be tied to the timecourse of speech perception. The current experiment involved written words.

There are, however, two observations of particular interest. First, derived-2 forms (relatively opaque derivationally related forms) patterned very much like meaning-1 forms in how often, over all, they were selected. At first glance, this might suggest that more distant derived forms are not always recognized as being morphologically related, but rather simply treated as somewhat semantically related forms, i.e., as though they were meaning- 1 forms. However, the pattern of competition was different for derived-2 and meaning-1 forms: derived-2 forms tended to lose out to other morphologically related forms (inflected, derived-1) more than the meaning-1 forms, while the meaning- 1 forms tended to have more competition from phonologically related forms (rhymes, cohorts) than the derived-2 forms did. This suggests that the more opaquely derived forms were recognized at least some of the time as being morphologically related, and specifically as being more distantly related than other morphologically related forms, while the semantically related forms were simply treated as a different category of relation. It is quite possible that different participants had different preferences for choosing morphologically, semantically, or phonologically related forms, although the overall tendencies are quite clear. Note, too, that when a derived- 2 form was in a pairwise relation with a meaning- 1 form, it was more often the derived-2 form that was selected, though both were common choices: 498 cases where derived-1 forms were chosen vs. 415 cases where meaning1 forms were chosen; an exact binomial test indicates that this difference is significant, $\mathrm{p}<0.01$. This again suggests that participants indeed distinguish between opaque derived forms and purely semantically related forms, at least some of the time.

The second particularly interesting observation is that although the categories do line up with the linguistically expected order, they are not at all absolute. While inflected forms, for example, are interpreted as being the most similar to root forms across the board, they were selected $83 \%$ of the time that they were an option, not $100 \%$. When inflected forms were not selected despite being an option, derived-1 and meaning-1 forms were the most likely to be selected instead, followed by derived-2 and meaning-2 forms, rhymes, and cohorts. Unrelated forms were also selected, though only $0.8 \%$ of the time (collapsing the two types of unrelated forms). Similar patterns are seen for the other types: when the given type was not itself chosen, the morphologically related forms, then semantically related forms, then phonologically related forms, and finally the unrelated ones were most likely to be chosen instead. There are several possible explanations for the lack of absolute preferences: first is, of course, simple error; participants could have made a selection that was unintended on any given trial. Given that the choices of types other than inflected forms themselves fall along the now-familiar continuum of relatedness, however, it seems unlikely that this explanation can be right for more than a handful of cases (especially, for example, the unrelated forms). Instead, it seems more likely that the overt nature of the task, where participants were explicitly asked to judge similarity between a root and some other form, may have caused participants to develop strategies, looking for words that they believe to be etymologically, semantically, or phonologically related. 


\section{DEVELOPING A PREDICTIVE MEASURE}

While the results of this behavioural study are encouraging in that they indicate that what linguists understand as morphological relatedness is also recognizable by naïve English speakers, what is of fundamental interest is whether it is possible to predict the degree to which pairs of words are perceived to be morphologically related on the basis of independent measures of similarity. That is, can independently calculated degrees of semantic, phonological, and orthographic similarity between a key word and a comparison word be used to predict the percentage of a time that that comparison word would be chosen in the behavioural study? The current section describes a logistic regression model intended to do exactly that.

\subsection{Modeling the original results}

Semantic relatedness ${ }^{8}$ was measured using the extended Lesk metric (Banerjee and Pedersen 2003). The relatedness between a pair of words is calculated as the sum of the square of the length of overlapping words in the definitions of the two words in WordNet (Princeton 2010), ignoring function words and other extremely common words. For example, two definitions that have one overlapping word would have a score of $1^{2}=1$; two definitions with two non-adjacent words overlapping would have a score of $1^{2}+1^{2}=2$; and two definitions with two adjacent words overlapping would have a score of $2^{2}=4$. In the extended version of this score, used here, definitions of hypernyms, hyponyms, metonyms, and other semantically related words are also included.

For orthographic and phonological similarity, we used a measure of string similarity developed by Khorsi (2012), who uses it as a direct measure of morphological relatedness itself. Given the typical linguistic assumption that morphological relatedness is also tied to semantic similarity, this measure is not used in isolation here, but it does provide a means of capturing basic form similarity. This measure takes the sum of the log of the inverse of the frequency of occurrence of each of the letters in the longest common shared sequence between two words, and subtracts the sum of the log of the inverse of the frequency of the letters that are not shared, as shown in (2). Khorsi (2012) applies this formula only to orthographic similarity, but it is easily transferred to phonological transcriptions, where the longest common shared sequence of phonemes is used instead. Spellings were based on Canadian English standards, as these were used for stimuli in the experiment. Transcriptions of the stimuli were based on the CMU dictionary pronunciations where available (CMU 2008) and otherwise transcribed using the CMU system by a linguistically trained native speaker of North American English. Token frequency values came from the

\footnotetext{
${ }^{8}$ The terms "semantic similarity" and "semantic relatedness" are used interchangeably in this paper. Both are used in the relatively broad sense sometimes associated more with "semantic relatedness," such that even words that are antonyms of each other are treated as more related or similar to each other than words that have no shared meaning.
} 

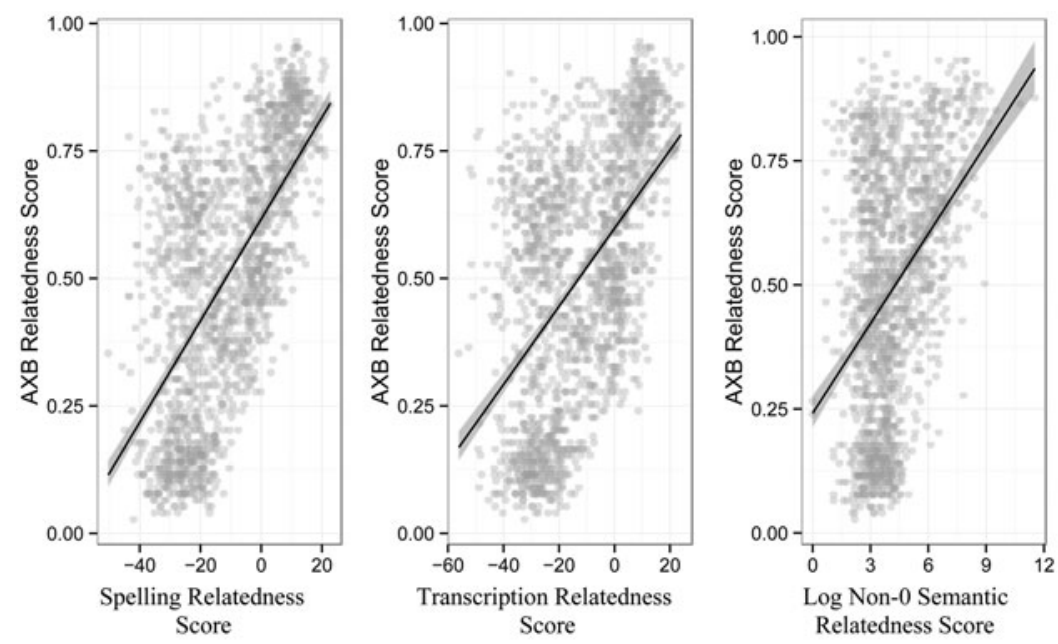

Figure 2: Correlations between individual measures of similarity between individual words and their key word, and the percentage of time each individual word was selected as being "more similar" to the key in all of its trials across all participants.

SUBTLEX corpus (Brysbaert and New 2009). These calculations of string similarity were carried out using the algorithms provided in the Phonological CorpusTools software package (Hall et al. 2015).

(2) Formula for string similarity from Khorsi (2012)

$\sum_{i=1}^{\left\|L C S\left(w_{1}, w_{2}\right)\right\|} \log \left(\frac{1}{\operatorname{freq}\left(\operatorname{LCS}\left(w_{1}, w_{2}\right)[i]\right)}\right)-\sum_{i=1}^{\| \overline{L C S\left(w_{1}, w_{2}\right) \|}} \log \left(\frac{1}{\operatorname{freq}\left(\overline{\operatorname{LCS}\left(w_{1}, w_{2}\right)[i]}\right)}\right)$

Note:

- $w_{1}, w_{2}$ are two words whose string similarity is to be measured

- $\operatorname{LCS}\left(w_{1}, w_{2}\right)$ represents the Longest Common Shared Sequence of symbols between the two words

Each of these three measures is, as expected, positively correlated with the probability of a particular comparison word being chosen when it is a choice. Figure 2 shows these correlations; the graph on the left shows orthographic similarity, that in the middle shows phonological similarity, and the graph on the right shows semantic similarity. Note that because the semantic similarity scores are exponential, the log of the scores is taken here to produce a relatively linear relation.

Although each correlation is in the direction expected, and each is significant at $\mathrm{p}<0.001$, the correlations are not particularly strong. The adjusted $\mathrm{R}^{2}$ for orthographic similarity is 0.39 ; that for phonological similarity is 0.27 ; and for semantic similarity, 0.16 . To get an actual predictor of perceived morphological relatedness, these three scores will need to be combined in a joint model. 


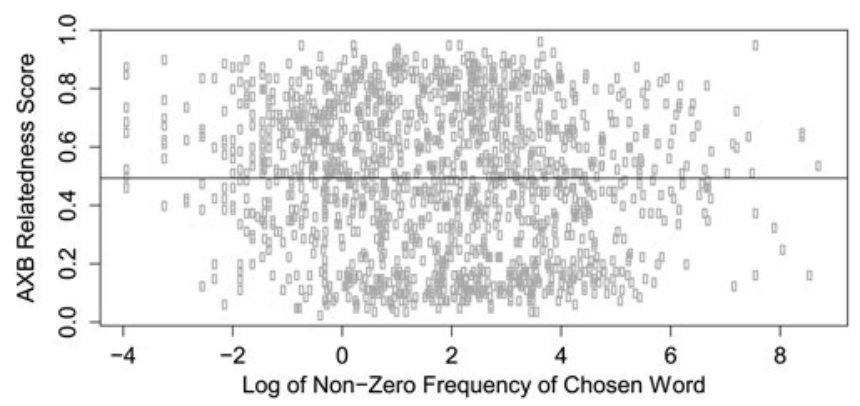

Figure 3: Lack of correlation between the percentage of the time a particular word was picked as being most similar to its key and the log of that word's token frequency in the SUBTLEX corpus.

One might expect frequency to play a role in such a model, as well. There was, however, no observed correlation between the (log) token frequency of a word's occurrence (taken from the SUBTLEX corpus; Brysbaert and New 2009) and its likelihood of being chosen, as shown in Figure 3; the $\mathrm{R}^{2}$ value for this correlation is $<0.001$, with a non-significant p-value of 0.72 . An examination of the relation between the (log) frequency ratio of word 1 to word 2 in any given triplet and the likelihood of word 1's being chosen in that triplet did show a significant correlation $(\mathrm{p}<0.001)$, but the $\mathrm{R}^{2}$ value was very small $(0.01)$, and the correlation was negative; see Figure 4 (note that for any single triplet, there are only five instances of its being evaluated in the experiment, because each triplet appeared in only one group, and each group had five participants). This negative correlation is at first surprising, in that it indicates a slight tendency for participants to select the less frequent word in any given pair. This may be due to the fact that many of the morphologically related words are in fact less frequent than the words chosen as semantically or phonologically related and the unrelated words. For example, for the keyword press, the inflected form, pressed, has a SUBTLEX frequency of 60.2 per million and the derived-1 form, pressure, has a frequency of $53.12 /$ million, while the

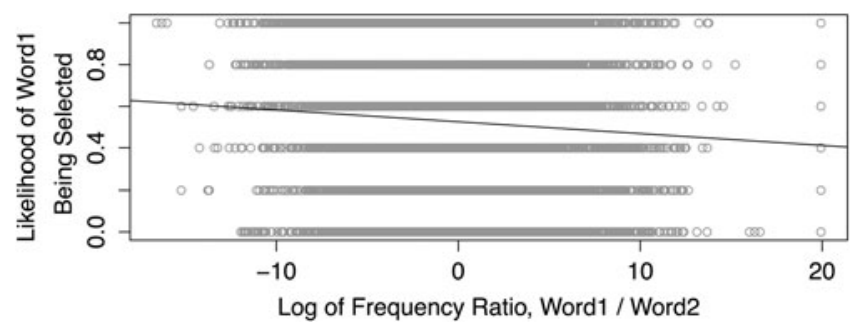

Figure 4: Slight negative correlation between the percentage of time word 1 in any given triplet was picked as being most similar to its key and the log of the ratio of the frequency between word 1 and word 2, with frequency taken as the token frequency in the SUBTLEX corpus. 


\begin{tabular}{lccc}
\hline \hline Summary & Component 1 & Component 2 & Component 3 \\
\hline Standard deviation & 1.360 & 1.000 & 0.387 \\
Proportion of variance & 0.617 & 0.333 & 0.050 \\
Cumulative proportion & 0.617 & 0.950 & 1.000 \\
\hline Loadings & Component 1 & Component 2 & Component 3 \\
\hline Spelling Similarity & 0.707 & & 0.707 \\
Transcription Similarity & 0.706 & & -0.706 \\
Log(Semantic Similarity) & & 0.998 & \\
\hline \hline
\end{tabular}

Table 4: Summary and loadings for the principal components analysis

meaning-1 form, push, has a frequency of 70.55/million; the rhyme form, mess, has a frequency of 78.14/million; and the unrelated-1 form, table, has a frequency of 105.63 million. Thus, while there may in fact be a role for frequency, it seems to be one that is itself driven by the fact that participants are more likely to pick morphologically related words as being similar, in spite of the fact that they are in many cases less frequent. Given the very small and apparently artifactual nature of the role of frequency, we do not include any measure of frequency in the joint model; instead, we include only orthographic, phonological, and semantic similarity.

Before creating the model, however, the issue of collinearity needs to be dealt with. Orthographic and phonological similarity scores will obviously be highly collinear, and semantic scores may also be collinear with either of the other two, given that many of the word pairs in question are morphologically related and thus share both form and meaning. To eliminate collinearity, then, a principal components analysis was run on the similarity scores for each comparison-key word pair. The resulting first two principal components accounted for $95 \%$ of the variance in these measures, and only these two components were subsequently used in the logistic regression. The first component accounted for $62 \%$ of the total variance and was based entirely on phonological and orthographic similarity, with the loadings of these two scores within the component almost equal. The second component accounted for $33 \%$ of the total variance and was based entirely on the (logged) semantic similarity scores. Thus, the principal components analysis provides a way of collapsing the original phonological, orthographic, and semantic similarity scores into two mutually exclusive components, one encoding the form-similarity between words and the other encoding the meaning-similarity. Details of the analysis are given in Table 4.

These first two components were then used in a logistic regression model that attempts to predict, given the two principal components of two word pairs (i.e., the form and meaning components for key comparison 1, along with the form and meaning components for key comparison 2), which of the two comparison words would be chosen as being "more similar" to the key (by predicting whether word 1 will be chosen on any given trial). Model selection was done by comparing 


\begin{tabular}{lrrrr}
\hline \hline Coefficients & Estimate & Std. Error & z-value & p-value \\
\hline (Intercept) & 0.114 & 0.010 & 11.185 & $<0.001$ \\
FC1 & 0.590 & 0.008 & 72.397 & $<0.001$ \\
MC1 & 0.597 & 0.011 & 54.307 & $<0.001$ \\
FC2 & -0.546 & 0.008 & -67.519 & $<0.001$ \\
MC2 & -0.565 & 0.011 & -52.056 & $<0.001$ \\
FC1:MC1 & -0.232 & 0.008 & -30.327 & $<0.001$ \\
FC1:FC2 & 0.014 & 0.006 & 2.266 & 0.024 \\
FC1:MC2 & 0.013 & 0.008 & -1.544 & 0.123 \\
MC1:FC2 & 0.017 & 0.009 & 2.017 & 0.044 \\
MC1:MC2 & 0.011 & 0.011 & 0.968 & 0.333 \\
FC2:MC2 & 0.211 & 0.007 & 28.287 & $<0.001$ \\
FC1:MC1:FC2 & 0.024 & 0.006 & 4.152 & $<0.001$ \\
FC1:MC1:MC2 & 0.013 & 0.008 & 1.667 & 0.095 \\
FC1:FC2:MC2 & -0.026 & 0.006 & -4.462 & $<0.001$ \\
MC1:FC2:MC2 & -0.023 & 0.008 & -3.048 & 0.002 \\
& & & & AIC: 62692 \\
\hline \hline
\end{tabular}

Table 5: Best-fit logistic regression model for predicting the likelihood of word 1 being chosen as more similar to a key word. FC1 is the form component for the comparison of the key word to word 1; MC1 is the meaning component of the comparison of the key word to word 1. FC2 and MC2 are the analogous components for the comparison of the key word to word 2.

models that had varying possible interactions among these four factors, with the best fit model being chosen as the one with the lowest Akaike information criterion (AIC), a measure of the information lost when using a particular model of the data that allows for direct comparison of non-nested models and penalizes the addition of extra parameters in the model. The resulting best fit model (shown in Table 5) relied on all four factors, along with up to three-way interactions among them. As can be seen from the estimates of the single term factors, the likelihood of selecting word 1 increases as a function of the form and meaning components of word 1 and decreases as a function of the form and meaning components of word 2, as expected. The interactions compensate for over- and under-estimates of selecting word 1 on any given trial based on the combination of the components.

The model was then applied to the original data to determine its classification accuracy, which was $73 \%$. That is, the model, which is based entirely on independently calculated scores of semantic, phonological, and orthographic similarity, correctly predicts which of two words our participants chose as being "more similar" to the key on $73 \%$ of trials. Note that the model is not expected to be able to predict with $100 \%$ accuracy, as different participants could have made different choices from each other on identical trials. 


\subsection{Testing the model against new words}

Even more usefully, however, the model can be used to generate predicted "perceived morphological relatedness" scores. This is done by entering a new key word + comparison word pair into the model, using calculated orthographic, transcription, and semantic similarity scores (transformed by the same principal component loadings as the original data). Predicted perceived morphological relatedness, then, is the model's calculated probability that this comparison word would be chosen as being more similar to the key, as compared to the average probability that a known unrelated word would have been chosen.

For example, consider a novel key-comparison pair, table $\sim$ tabulate. The raw orthographic similarity score for this pair is -9.644 ; the transcription similarity score is -29.672 ; and the semantic similarity score is 87 . These scores are then subjected to the same loadings as the original principal components analysis (first taking the log of the semantic score), ${ }^{9}$ leading to a score of -0.565 for the "form" component and 0.152 for the "meaning" component.

We can then compare these values to the mean values for unrelated key-comparison pairs from the original dataset, which are -1.208 for the form component and -0.420 for the meaning component. These four components are entered as new values into the best-fit logistic regression model from Table 5 above, to produce the probability that table tabulate would be chosen as being "more similar" than table vs. an unrelated word. This last step is done automatically by using the predict() function of the stats software package in R (R Core Team 2014), with the "type" argument set to "response," so that probabilities are returned instead of log-odds. A score of $50 \%$ would indicate that tabulate is just as likely to be chosen as more similar to table as an average unrelated word (i.e., there is a 50-50 chance that either will be chosen), while a score of $100 \%$ would indicate that tabulate is always going to be chosen over an unrelated word. Thus, a score of $50 \%$ is indicative of a novel word's being an unrelated form, while a score of $100 \%$ is indicative of its being highly related to the key. The actual value in this case is $71 \%$, which seems to line up with native-speaker intuitions, in that tabulate is clearly more related to table than an unrelated word would be, but is not as related as an inflected form like tables would be.

Less anecdotally, the model can be tested on an entire set of new key + comparison pairs. 11 novel key words with each of their 9 comparison forms were selected, using the same guidelines as the stimuli used in the behavioural study. Table 6 shows the predicted probability that each class of comparison word will be chosen, as compared to the average unrelated form from the original study.

The word classes in Table 6 are listed in the order in which they emerged in the original study. Most of the classes emerge in the predictions in the same order, with the novel unrelated forms being selected at chance $(48.45 \%, 52.78 \%)$ as compared

\footnotetext{
${ }^{9}$ Note that as part of the principal components analysis, a z-score normalization is carried out. The same z-score transformation is therefore applied to the novel data before the loadings are applied.
} 


\begin{tabular}{lc}
\hline \hline Type of Comparison & Probability \\
\hline inflected & $91.30 \%$ \\
derived-1 & $86.41 \%$ \\
derived-2 & $72.94 \%$ \\
meaning-1 & $72.94 \%$ \\
meaning-2 & $73.38 \%$ \\
rhyme & $\mathbf{8 1 . 8 0} \%$ \\
cohort & $68.42 \%$ \\
unrelated-1 & $48.45 \%$ \\
unrelated-2 & $52.78 \%$ \\
\hline \hline
\end{tabular}

Table 6: Probabilities for novel words to be selected as more similar to their key word, as compared to an average unrelated word.

to the original unrelated forms, and inflected forms being highly likely to be chosen, at $91.30 \%$. At the same time, the model over-predicts rhymes, predicting that they will be chosen over an unrelated form $81.80 \%$ of the time, which would put them between transparent and opaque derivationally related forms.

As in the original model, derived-2 forms are not significantly different from meaning-1 forms [t $(20)<0.001, \mathrm{p}>0.99$ ], with both being predicted to be chosen over an unrelated form around $73 \%$ of the time. However, there is also no difference in this model between the two types of semantically related forms $[\mathrm{t}(20)=0.0765$, $p=0.94]$. Meaning- 2 forms are also predicted to be chosen over unrelated forms approximately $73 \%$ of the time. One possible explanation for this anomaly is that the extended Lesk semantic similarity scores are simply based on shared meaning, while the difference between the two semantic forms in the stimuli - "primary" vs. "secondary" meanings - is based on the frequency of use of the two meanings. That is, what is here referred to as the "primary meaning" of the word is simply the most common conventional meaning of the word, and the "secondary meaning" is a less common conventional meaning; the Lesk scores do not take frequency of use into account. Thus, it is quite possible that human participants were less able or less likely to see the relation between, say, press and media, than the model was, since the more frequent meaning of press is something more like push.

\subsection{Implications}

Based on the predictive results in $\S 5.2$, there does seem to be a relatively clear distinction between the first two types of morphologically related forms - that is, inflected forms and transparently derived forms - and all other potentially "related" forms. Specifically, words that are predicted to be chosen at least $82 \%$ of the time as being more similar to a key word than an unrelated word could be considered to be perceived as morphologically related to the key word (or, given a slightly more conservative estimate, those predicted to be chosen at least $86 \%$ of the time). Taking the average of these two potential cut-off values gives us a cut-off value of 


\begin{tabular}{llcl}
\hline \hline Key & $\begin{array}{l}\text { Possible } \\
\text { related word }\end{array}$ & $\begin{array}{l}\text { Predicted Perceived Morphological } \\
\text { Relatedness Score }\end{array}$ & $\begin{array}{l}\text { Counts as } \\
\text { morphologically related? }\end{array}$ \\
\hline \multirow{2}{*}{ face } & type-face & $88.51 \%$ & yes \\
& facial & $84.24 \%$ & yes \\
& face-lift & $80.66 \%$ & no \\
& facet & $77.28 \%$ & no \\
façade & $76.61 \%$ & no \\
superficial & $55.77 \%$ & no \\
\hline \hline
\end{tabular}

Table 7: Predicted perceived morphological relatedness scores for a set of words that are etymologically related to face. Predicted scores of $84 \%$ or greater are treated as being "morphologically related."

$84 \%$. Thus, if one were interested in knowing whether a particular alternation is psychologically "real" to naïve English speakers, and thus whether it could be counted as an actual alternation for the purposes of determining the relative frequency of different alternations in the language, one could simply calculate the semantic, orthographic, and transcription similarities of the words potentially involved in the alternation and put them into the model; scores above $84 \%$ would count as being viable alternations, while scores below this cut-off would be excluded.

As an example, we return to the issue of $[s] \sim\left[\int\right]$ alternations in English. Recall that Johnson and Babel (2010) claim that the frequency of this alternation is low enough as to not have an impact on their phonological relationship, with the two sounds simply being considered as contrastive. To calculate the actual frequency of this alternation, then, we need to count the number of words that participate in alternations between [s] and [ $]$ ] and compare that to the number of words that have only [s] or []], with no alternation. To determine whether any particular word, such as facial or superficial, should belong to the first (alternating) set or the second (non-alternating) set, we can use their predicted perceived morphological relatedness score. Table 7 provides the calculations based on the logistic regression model in Table 5.

Thus, using $84 \%$ as the cut-off between being morphologically related and not, only type-face and facial would be considered to be related to face, while face-lift, facet, façade, and superficial would not.

Turning to the entire lexicon of English, we can similarly estimate the overall frequency of the $[s] \sim\left[\int\right]$ alternation by first extracting all pairs of words from a dictionary (in this case, the Irvine Phonotactic Online Dictionary; Vaden et al. 2009) where one of the words contains [s] and the other contains [S]; there are $66,097,250$ such pairs in total. We then calculated the phonetic, orthographic, and semantic similarity of each of these pairs, subjected them to the z-score normalization and principal components analysis as described above, and applied the logistic regression algorithm to them to calculate the predicted perceived morphological relatedness of each pair. We then used the cut-off of $84 \%$ to determine categorically 
whether each pair should be considered to be perceived to be morphologically related (and thus a possible alternation) or not. This procedure determines that 9,991 of the total pairs are predicted to be perceived to be morphologically related. Many of these pairs, however, do contain [s] and []] but are clearly not eligible to be counted as alternations, simply because the two sounds are not aligned with each other (e.g., it predicts that mustache is related to mustaches and that cite is related to citation, both of which are indubitably true but not representative of actual [s] [J] alternations). Thus, we subjected this set of pairs to a phonological alignment algorithm (again, found in Phonological CorpusTools; Hall et al. 2015) to exclude all pairs where [s] and [S] are not aligned. The algorithm first calculates the Levenshtein edit distance alignment between the two words, except that it assigns no penalty to [s] [ [] substitutions. The algorithm then tests each pair to see whether the two words contain a common "core" of at least two segments, and specifically checks to see whether the aligned cores between the two words are either identical or have a difference only in [s] vs. [ $]$, with cores that don't have an [s] [J] substitution being excluded as not a potential alternation. This alignment algorithm narrows the original list of "related" word pairs from 9,991 to 251 .

Finally, we count the number of unique [s]- or [f]-containing words that occur in those 251 pairs (373), and compare that to the number of unique [s]- or [ $]$ ]-containing words in the entire corpus $(20,126)$, for a "frequency of alternation" of $1.85 \% .{ }^{10}$

This procedure does still somewhat overestimate the frequency of alternation (e.g., it predicts that class and clash are related and have an aligned alternation of [s] [S], presumably because of the relatively high form similarity between the two, other than the difference between [s] and [f]). Most of the words on the final list do, however, seem to accord with our intuitions of alternating forms (e.g., oppress oppression; prejudice $\sim$ prejudicial), with the advantage being that they are arrived at entirely objectively on the basis of their shared phonetic, orthographic, and semantic characteristics. Thus, this method does give us an upper bound on the frequency of the alternation, and in this case, the absolute value of less than $2 \%$ seems intuitively "low." Without doing similar calculations in other languages, or on other alternations within English, however, it is hard to know whether this is a relatively "frequent" or "infrequent" alternation. That said, one can certainly imagine that in a language where all instances of $\left[\int\right]$ are derived from $/ \mathrm{s} /$, the frequency would be higher. That

\footnotetext{
${ }^{10}$ Note that this results in a slightly different means of calculating frequency of alternation than that described in section 1, where it was proposed that the frequency should be calculated as the number of words that contain morphemes that have both [s]- and [ $]$-ful allomorphs, divided by the number of words that contain morphemes that have only [s]- or []]-containing allomorphs. That method would require "transitivity" of morphological relatedness to be assumed, e.g., if facial is related to face, and face is related to type-face, then facial is related to type-face. We don't believe that our data speak to this issue; after all, the two face key words could in fact be interpreted as unrelated homophones. We therefore restrict the calculation to the number of words that themselves are actively predicted to be morphologically related to a word containing the "other" fricative, divided by the total number of [s]- and [s]containing words.
} 


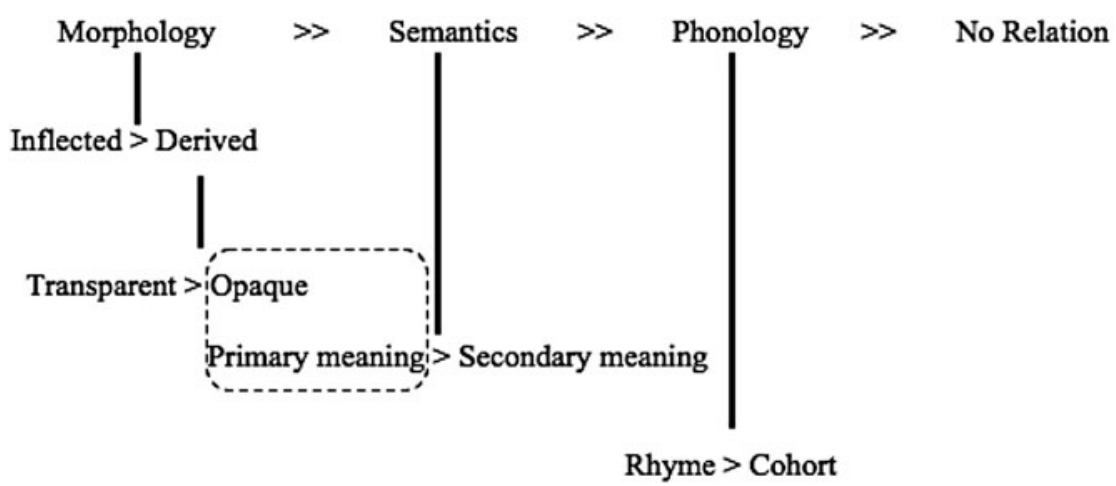

Figure 5: Overall perceived morphological relatedness

is, the claim of Johnson and Babel (2010) that the [s] [J] alternation is infrequent in English cannot be verified or denied by this measure, but we now have a way of actually quantifying the degree of perceived alternation. This can in turn be used to determine the extent to which two sounds must alternate in order to be considered meaningful by speakers in determining phonological relations.

\section{CONClusions}

In conclusion, we have shown that an explicit similarity judgement task can reveal perceived morphological similarity on the part of English speakers; the judgements of such speakers do tend to line up with the intuitions of linguists. Specifically, similarity reveals the relations shown in Figure 5. Morphologically related words tend to be judged as more similar than semantically related words, which in turn are judged as more similar than phonologically related words. Within morphologically related words, inflected forms are more similar to base words than derived forms are, and within derived forms, more transparent forms are more similar to base forms than more opaque forms are. Within semantically related words, more frequently used conventional meanings are treated as being more similar to base words than less frequently used meanings. And within phonologically related words, rhyming words are treated as more similar to base words than cohort words are. All of these types of relations are recognized as resulting in more similarity than is present with intentionally unrelated words.

It is still somewhat unclear what the difference between opaque derivationally related forms and semantically related forms might be. While there is some evidence that these two classes of words are treated the same way by speakers, there is also some evidence of at least slight recognition of derived forms as being more similar than semantically related forms. Prior studies have similarly found that derived forms are not processed the same way as semantically related forms, though the results of these studies are not entirely consistent. Indeed, there may be variation even in terms of individual forms. As Gonnerman et al. (2007) found, 
morphologically complex words may or may not prime each other, depending on how phonologically and semantically related they actually are. There also seems to be cross-linguistic variation; Smolka et al. (2014), for instance, found that German speakers treated opaque derivationally related forms the same as transparently derived forms, but not like semantically related forms.

In addition to these general findings about the rated similarity of pairs of words, we have attempted to show that the perceived morphological relatedness of novel words can be estimated from measures of orthographic, phonological, and semantic similarity. This measure can in turn be used to determine whether particular words might constitute psychologically realistic alternations, thus allowing for the calculation of the frequency with which particular pairs of sounds alternate in a language.

While we think that the measures developed here are a good first step, we would like to see future research develop even stronger measures. For example, a measure of the frequency with which different conventional meanings of a word are used could help tease apart the behavioural differences between primary vs. secondary meaning forms. It is also possible that other measures of semantic, orthographic, or phonological similarity might result in a higher classification accuracy for the original logistic regression, in turn yielding stronger results for the predicted perceived morphological relatedness measures. Furthermore, the model proposed here is quite obviously language-dependent; in order to usefully compare frequency of alternations across multiple languages, for example, one would need to conduct similar studies on the perceived morphological relatedness of words within those languages. Furthermore, we would not anticipate that even the order of results would be the same across languages; Smolka et al. (2014), for example, find that the patterns of semantic and morphological priming in German are quite different from that in other IndoEuropean languages, such as the results for Dutch found in Zwitserlood et al. (2004).

In the meantime, though, it is our hope that the proposed metric can be used to develop a more psychologically plausible picture of phonological alternations, based on the perceived morphological relatedness of potential alternations.

\section{REFERENCES}

Allopenna, Paul D., James S. Magnuson, and Michael Tanenhaus. 1998. Tracking the time course of spoken word recognition using eye movements: Evidence for continuous mapping models. Journal of Memory and Language 38(4): 419-439.

Aronoff, Mark. 1976. Word formation in Generative Grammar. Cambridge, MA: MIT Press. Baayen, R. Harald. 2014. Experimental and psycholinguistic approaches to studying derivation. In The Oxford handbook of derivational morphology, ed. Rochelle Lieber and Pavol Stekauer, 95-117. Oxford: Oxford University Press.

Baayen, R. Harald, Ton Dijkstra, and Robert Schreuder. 1997. Singulars and plurals in Dutch: Evidence for a parallel dual-route model. Journal of Memory and Language 37(1): 94-117.

Baayen, R. Harald, Willem M. J. Levelt, Robert Schreuder, and Mirjam Ernestus. 2008. Paradigmatic structure in speech production. Proceedings of the Chicago Linguistics Society 43: 1-29. 
Baayen, R. Harald, Petar Milin, Dusica Filipović Đurđević, Peter Hendrix, and Marco Marelli. 2011. An amorphous model for morphological processing in visual comprehension based on naive discriminative learning. Psychological Review 118: 438-481.

Banerjee, Satanjeev and Ted Pedersen. 2003. Extended gloss overlaps as a measure of semantic relatedness. In Proceedings of the Eighteenth International Joint Conference on Artificial Intelligence, 805-810.

Bauer, Laurie. 1997. Evaluative morphology: A search for universals. Studies in Language 21(3): 533-575.

Bien, Heidrun, R. Harald Baayen, and Willem J. M. Levelt. 2011. Frequency effects in the production of Dutch deverbal adjectives and inflected verbs. In Morphology in language comprehension, production, and acquisition, ed. Raymond Bertram, Jukka Hyönä and Matti Laine, 683-715. London: Psychology Press.

Booij, Geert. 1995. The phonology of Dutch. Oxford: Oxford University Press.

Boomershine, Amanda, Kathleen Currie Hall, Elizabeth Hume, and Keith Johnson. 2008. The influence of allophony vs. contrast on perception: the case of Spanish and English. In Contrast in phonology: perception and acquisition, ed. Peter Avery, B. Elan Dresher and Keren Rice, 145-171. Berlin: Mouton.

Brysbaert, Marc and Boris New. 2009. Moving beyond Kučera and Francis: A critical evaluation of current word frequency norms and the introduction of a new and improved word frequency measure for American English. Behavior Research Methods 41(4): 977-990.

Burani, Cristina, and Alfonso Caramazza. 1987. Representation and processing of derived words. Language and Cognitive Processes 2(3-4): 217-227.

Carlisle, Joanne F. 1988. Knowledge of derivational morphology and spelling ability in fourth, sixth, and eighth graders. Applied Psycholinguistics 9(3): 247-266.

CMUDict (The Carnegie Mellon Pronouncing Dictionary. 2008. Pittsburgh, PA: Carnegie Mellon University.

Feldman, Laurie Beth. 2000. Are morphological effects distinguishable from the effects of shared meaning and shared form? Journal of Experimental Psychology: Learning, Memory, and Cognition 26: 1431-1444.

Feldman, Laurie Beth, Emily G. Soltano, Matthew J. Pastizzo, and Sarah E. Francis. 2004. What do graded effects of semantic transparency reveal about morphological processing? Brain and Language 90(1-3): 17-30.

Forster, Kenneth I., and Susan M. Chambers. 1973. Lexical access and naming time. Journal of Verbal Learning and Verbal Behavior 12(6): 627-635.

Frost, Ram, Avital Deutsch, Orna Gilboa, Michal Tannenbaum, Michal, and William MarslenWilson. 2000. Morphological priming: Dissociation of phonological, semantic, and morphological factors. Memory \& Cognition 28(8): 1277-1288.

Gonnerman, Laura M., Mark S. Seidenberg, and Elaine S. Andersen. 2007. Graded semantic and phonological similarity effects in priming: Evidence for a distributed connectionist approach to morphology. Journal of Experimental Psychology: General 136(2): 323-345.

Gussenhoven, Carlos. 1999. Illustrations of the IPA: Dutch. Handbook of the international phonetic association. Cambridge: Cambridge University Press. 74-77.

ten Hacken, Pius. 2013. Diminutives and plurals of Dutch nouns. Quaderns de Filologia. Estudis lingüístics XVIII: 61-70.

Hall, Kathleen Currie, Blake Allen, Michael Fry, Scott Mackie, and Michael McAuliffe. 2015. Phonological CorpusTools, Version 1.0. [Computer program]. Available from https:// sourceforge.net/projects/phonologicalcorpustools/.

Hay, Jennifer. 2003. Causes and consequences of word structure. New York and London: Routledge. 
Johnson, Keith and Molly Babel. 2010. On the perceptual basis of distinctive features: Evidence from the perception of fricatives by Dutch and English speakers. Journal of Phonetics 38(1): 127-136.

Khorsi, Ahmed. 2012. On morphological relatedness. Natural Language Engineering 19(4): 537-555.

Longtin, Catherine-Marie, Juan Segui, and Pierre A. Hallé. 2003. Morphological priming without morphological relationship. Language and Cognitive Processes 18(3): 313-334.

Lu, Yu-an. 2012. The role of alternation in phonological relationships. Doctoral dissertation, Stony Brook University.

Marslen-Wilson, William, Lorraine Komisarjevsky Tyler, Rachelle Waksler, and Lianne Older. 1994. Morphology and meaning in the English mental lexicon. Psychological Review 101: 3-33.

Marslen-Wilson, William and Pienie Zwitserlood. 1989. Accessing spoken words: The importance of word onsets. Journal of Experimental Psychology: Human Perception and Performance 15(3): 576-585.

Meunier, Fanny, and Juan Segui. 1999. Frequency effects in auditory word recognition: The case of suffixed words. Journal of Memory and Language 41(3): 327-344.

Morris, Joanna, Tiffany Frank, Jonathan Grainger, and Philip J. Holcomb. 2007. Semantic transparency and masked morphological priming: An ERP investigation. Psychophysiology 44(4): 506-521.

Moscoso del Prado Martín, Fermín. 2003. Paradigmatic structures in morphological processing: Computational and cross-linguistic experimental studies. Doctoral dissertation, Radboud University Nijmegen.

Murrell, Graham A., and John Morton. 1974. Word recognition and morphemic structure. Journal of Experimental Psychology 102(6): 963-968.

Napps, Shirley E., and Carol A. Fowler. 1987. Formal relationships among words and the organization of the mental lexicon. Journal of Psycholinguistic Research 16(3): 257-272.

Napps, Shirley E. 1989. Morphemic relationships in the lexicon: Are they distinct from semantic and formal relationships? Memory \& Cognition 17(6): 729-739.

Pastizzo, Matthew J., and Laurie Beth Feldman. 2009. Multiple dimensions of relatedness among words: Conjoint effects of form and meaning in word recognition. The Mental Lexicon 4(1): 1-25.

Pluymaekers, Mark, Mirjam Ernestus, and R. Harald Baayen. 2005. Lexical frequency and acoustic reduction in spoken Dutch. Journal of the Acoustical Society of America 118 (4): 2561-2569.

Princeton University. 2010. About WordNet. WordNet. http://wordnet.princeton.edu.

Psychology Software Tools, Inc. [E-Prime 2.0]. 2012. Retrieved from http://www.pstnet.com.

R Core Team. 2014. R: A language and environment for statistical computing. R Foundation for Statistical Computing, Vienna, Austria. http://www.R-project.org/.

Radeau, Monique, Mireille Besson, Elisabeth Fonteneau, and Sao Luis Castro. 1998. Semantic, repetition, and rime priming between spoken words: Behavioral and electrophysiological evidence. Biological Psychology 48(2): 183-204.

Seidenberg, Mark S., and Laura M. Gonnerman. 2000. Explaining derivational morphology as the convergence of codes. Trends in Cognitive Sciences 4(9): 353-361.

Seidenberg, Mark S., and James L. McClelland. 1989. A distributed, developmental model of word recognition and naming. Psychological Review 96(4): 523-568.

Silverman, Daniel. 2006. A critical introduction to phonology: of sound, mind, and body. London/New York: Continuum. 
Smolka, Eva, Katrin H. Preller, and Carsten Eulitz. 2014. 'Verstehen' ('understand') primes 'stehen' ('stand'): Morphological structure overrides semantic compositionality in the lexical representation of German complex verbs. Journal of Memory and Language 72: $16-36$.

Sternberg, Robert J. and Powell, Janet S. 1983. Comprehending verbal comprehension. American Psychologist 38(8): 878-893.

Stockall, Linnaea, and Alec Marantz. 2006. A single route, full decomposition model of morphological complexity: MEG evidence. The Mental Lexicon 1(1): 85-123.

Tabak, Wieke, Robert Schreuder, and R. Harald Baayen. 2010. Producing inflected verbs: A picture naming study. The Mental Lexicon 5(1): 22-46.

Taft, Marcus, and Kenneth I. Forster. 1975. Lexical storage and retrieval of prefixed words. Journal of Verbal Learning and Verbal Behavior 14(6): 638-647.

Tyler, Andrea, and Nagy, William. 1989. The acquisition of English derivational morphology. Journal of Memory and Language 28(6): 649-667.

Vaden, Kenneth I., H. R. Halpin and G. S. Hickok. 2009. Irvine Phonotactic Online Dictionary. Version 2.0. [Data file]. Available from http://www.iphod.com.

$\mathrm{Xu}$, Joe, and Marcus Taft. 2015. The effects of semantic transparency and base frequency on the recognition of English complex words. Journal of Experimental Psychology: Learning, Memory, and Cognition 41(3): 904-910.

Zwitserlood, Pienie, Agnes Bolwiender, and Etta Drews. 2004. Priming morphologically complex verbs by sentence contexts: Effects of semantic transparency and ambiguity. Language and Cognitive Processes 20(1): 395-415. 


\section{APPENDIX}

PART A: Stimuli for EXPERIMENT

\begin{tabular}{|c|c|c|c|c|c|c|c|c|c|}
\hline Key: & Inflected & Derived 1 & Derived 2 & Meaning 1 & Meaning 2 & Rhyme & Cohort & Unrelated 1 & $\begin{array}{l}\text { Unrelated } \\
2\end{array}$ \\
\hline able & ablest & ability & capability & skill & strong & sable & ate & ruby & turquoise \\
\hline access & accessed & accession & accessory & approach & get & digress & accent & graph & chart \\
\hline amble & ambled & ambulate & ambulance & stroll & step & bramble & at & magnet & milkshake \\
\hline amuse & amused & amuse- & amusedly & divert & laugh & sues & amulet & thumb & leg \\
\hline analyze & analyzed & $\begin{array}{c}\text { ment } \\
\text { analysis }\end{array}$ & misanalyzed & examine & dissect & $\begin{array}{l}\text { com- } \\
\text { promise }\end{array}$ & analogy & stoop & purse \\
\hline angle & angles & angular & triangulate & intersection & lean & strangle & anxious & dinner & breakfast \\
\hline antique & antiques & antiquity & antiquated & old & furniture & cheek & antifreeze & wrap & load \\
\hline arbor & arbors & arboretum & arboricultural & tree & spindle & barber & army & vest & gown \\
\hline ball & balls & baller & balloon & globe & dance & wall & bottom & clover & cotton \\
\hline benefit & benefits & beneficial & beneficiary & profit & welfare & definite & benevolent & rosy & golden \\
\hline bind & bound & binder & boundary & adhere & obligate & rind & bike & coat & hat \\
\hline blood & blooded & bloody & bloodlessness & fluid & lineage & thud & blunder & cardigan & overcoat \\
\hline boss & bosses & bossy & bossyness & foreman & order & floss & box & needle & hammer \\
\hline boy & boys & boyhood & boyishness & lad & youth & toy & buoyant & light & frame \\
\hline build & built & builder & rebuild & construct & establish & killed & bitter & earring & lipstick \\
\hline burn & burning & burnable & unburned & combust & incinerate & churn & burst & sandwich & freezer \\
\hline calm & calmed & calmness & calmingly & serene & tranquilize & balm & cough & glue & pin \\
\hline cart & carts & cartwheel & pushcart & haul & wagon & dart & carpet & waffle & nylon \\
\hline cat & cats & catty & uncatlike & feline & jazz-fan & bat & castle & green & blue \\
\hline cause & caused & causal & causation & induce & reason & pause & caught & tissue & printer \\
\hline
\end{tabular}

(Appendix. cont.) 
(Cont.)

\begin{tabular}{|c|c|c|c|c|c|c|c|c|c|}
\hline Key: & Inflected & Derived 1 & Derived 2 & Meaning 1 & Meaning 2 & Rhyme & Cohort & Unrelated 1 & $\begin{array}{l}\text { Unrelated } \\
2\end{array}$ \\
\hline cave & caves & cavern & excavate & hollow & spelunk & wave & care & paper & pencil \\
\hline cease & ceased & ceaseless & cessation & end & discontinue & fleece & seed & rug & bag \\
\hline centre & centers & central & concentrate & heart & focus & renter & seldom & leak & pond \\
\hline chase & chasing & chaser & purchase & pursue & track & base & chair & coffee & cocoa \\
\hline check & checked & check-out & checkless & bill & ensure & deck & cherub & golden & neutron \\
\hline claim & claims & claimant & exclamation & assert & demand & tame & clay & fruit & toast \\
\hline class & classes & classify & classification & sort & category & grass & clan & orchid & tinfoil \\
\hline clean & cleaning & cleanly & cleanliness & $\begin{array}{l}\text { decon- } \\
\text { taminate }\end{array}$ & purify & green & cleats & booster & robber \\
\hline clock & clocks & clockwork & $\begin{array}{l}\text { counter- } \\
\text { clockwise }\end{array}$ & timepiece & watch & stock & closet & grizzly & redwood \\
\hline close & closed & closet & enclosure & shut & block & toes & cloak & cheddar & rascal \\
\hline colour & colours & colourize & discolouration & tinge & interest & muller & cult & grandpa & reason \\
\hline compile & compiled & compiler & compilation & store & accumulate & revile & command & percussion & artery \\
\hline complex & complexes & $\begin{array}{l}\text { com- } \\
\text { plexion }\end{array}$ & complication & $\begin{array}{l}\text { inter- } \\
\text { connected }\end{array}$ & composite & perplex & complete & necklace & bracelet \\
\hline compose & composed & composure & composition & form & make & froze & command & ballpoint & saltlick \\
\hline compute & computed & computer & computation & cipher & calculate & flute & compare & sticky & messy \\
\hline congress & con-gresses & $\begin{array}{l}\text { con- } \\
\text { gression }\end{array}$ & congressional & legislature & council & progress & convoy & giraffe & snowboard \\
\hline $\begin{array}{l}\text { contend } \\
\text { courage }\end{array}$ & $\begin{array}{l}\text { contended } \\
\text { courages }\end{array}$ & $\begin{array}{l}\text { contention } \\
\text { coura- } \\
\text { geous }\end{array}$ & $\begin{array}{l}\text { contendingly } \\
\text { encourage- } \\
\text { ment }\end{array}$ & $\begin{array}{l}\text { assert } \\
\text { bravery }\end{array}$ & $\begin{array}{l}\text { postulate } \\
\text { spunk }\end{array}$ & $\begin{array}{l}\text { pretend } \\
\text { forage }\end{array}$ & $\begin{array}{l}\text { condor } \\
\text { current }\end{array}$ & $\begin{array}{l}\text { mahogany } \\
\text { pencil }\end{array}$ & $\begin{array}{l}\text { cultural } \\
\text { peanut }\end{array}$ \\
\hline craze & crazed & crazy & crazily & demented & wild & daze & crane & hammer & staple \\
\hline create & created & creative & recreation & make & cause & abate & creepy & pie & tie \\
\hline
\end{tabular}




\begin{tabular}{|c|c|c|c|c|c|c|c|c|c|}
\hline credit & credits & credible & creditation & attribute & charge & edit & Kremlin & Easter & bamboo \\
\hline crown & crowned & coronate & coronation & monarch & peak & town & crowded & jacket & nature \\
\hline $\begin{array}{l}\text { crust } \\
\text { cup }\end{array}$ & $\begin{array}{l}\text { crusts } \\
\text { cups }\end{array}$ & $\begin{array}{l}\text { crusty } \\
\text { cupful }\end{array}$ & $\begin{array}{l}\text { encrustation } \\
\text { cuplike }\end{array}$ & $\begin{array}{l}\text { shell } \\
\text { container }\end{array}$ & $\begin{array}{l}\text { cheekiness } \\
\text { concavity }\end{array}$ & $\begin{array}{l}\text { must } \\
\text { pup }\end{array}$ & $\begin{array}{l}\text { crumble } \\
\text { cuddle }\end{array}$ & $\begin{array}{l}\text { blouse } \\
\text { airplane }\end{array}$ & $\begin{array}{l}\text { glove } \\
\text { snicker }\end{array}$ \\
\hline cut & cuts & cutter & uncuttable & tear & gash & rut & cub & lace & ice \\
\hline cycle & cycles & cyclic & cyclone & round & recur & Michael & siphon & tennis & backpack \\
\hline decide & decided & decision & decidedly & resolve & settle & override & December & kibbles & trackpants \\
\hline define & defined & definition & definitive & specify & quantify & consign & defiant & hairball & weasel \\
\hline democrat & democrats & democracy & $\begin{array}{l}\text { demo- } \\
\text { cratically }\end{array}$ & equality & $\begin{array}{l}\text { common- } \\
\text { wealth }\end{array}$ & diplomat & demonstrate & bacon & oatmeal \\
\hline destroy & destroyed & destroyer & destruction & undo & erase & employ & distrust & planet & pocket \\
\hline discuss & discussed & discussion & discussional & address & mention & bus & discolour & straw & pen \\
\hline display & displayed & redisplay & undisplaying & exhibit & show & relay & disperse & meatball & magic \\
\hline dive & diving & postdive & divemaster & plunge & descend & chive & dial & scrapbook & doghouse \\
\hline divide & divided & division & undividing & split & separation & inside & divine & cabbage & ferret \\
\hline doctor & doctors & doctorial & indoctrinate & physician & fix & proctor & dollop & cherry & chestnut \\
\hline dominate & dominated & $\begin{array}{l}\text { domi- } \\
\text { nation }\end{array}$ & predominance & prevail & overlook & $\begin{array}{l}\text { abo- } \\
\text { minate }\end{array}$ & daughter & paint & brush \\
\hline duct & ducts & aqueduct & conduction & channel & tube & lucked & dusk & loafer & shoelace \\
\hline emit & emitted & emission & emissary & expel & discharge & legit & emu & roof & floor \\
\hline equal & equals & equality & equilibrium & equivalent & peer & sequel & E-bay & plug & turn \\
\hline explain & explained & $\begin{array}{l}\text { expla- } \\
\text { nation }\end{array}$ & explanatorily & inform & instruct & insane & export & postman & textbook \\
\hline face & faced & facial & resurface & front & confront & pace & fate & lamp & knife \\
\hline fact & facts & factoid & factually & information & truth & tact & fan & headphone & window \\
\hline fall & fell & fallen & waterfall & descend & decrease & mall & father & slipper & shoelace \\
\hline fame & famed & famous & infamy & celebrity & renown & game & fair & wheel & cake \\
\hline fan & fans & fandom & fanatically & blower & devotee & man & fat & elbow & shoulder \\
\hline farm & farms & farmable & farmership & ranch & raise & alarm & farther & sappy & empty \\
\hline finite & finites & finiteness & infinity & limited & tensed & night & final & aunt & niece \\
\hline
\end{tabular}

(Appendix. cont.) 
(Cont.)

\begin{tabular}{|c|c|c|c|c|c|c|c|c|c|}
\hline Key: & Inflected & Derived 1 & Derived 2 & Meaning 1 & Meaning 2 & Rhyme & Cohort & Unrelated 1 & $\begin{array}{l}\text { Unrelated } \\
2\end{array}$ \\
\hline flux & fluxes & influx & fluently & flow & liquefy & ducks & flub & rock & pain \\
\hline form & forms & formation & conformity & descriptor & make & storm & force & sticky & tasty \\
\hline gas & gases & gaseous & gaseosity & steam & attack & lass & gap & lion & seahawk \\
\hline germ & germs & germicide & germination & seed & bug & firm & jerk & space & time \\
\hline grade & grades & gradual & degradation & class & level & jade & graze & buy & shop \\
\hline grain & grains & grainy & granulated & particle & cereal & abstain & great & hot & cold \\
\hline grant & granted & granter & grantee & allow & award & plant & grasp & keyboard & yogurt \\
\hline grasp & grasped & graspless & ungraspable & hold & clutch & clasp & grand & donkey & wildlife \\
\hline grate & grated & gratelike & grateless & grid & irritate & state & grape & cowhide & bungee \\
\hline gratify & gratified & $\begin{array}{l}\text { grati- } \\
\text { fication }\end{array}$ & gratuity & satisfy & indulge & classify & gradual & sugar & carrot \\
\hline habit & habits & habituate & inhabitable & tradition & abuse & rabbit & handy & beach & box \\
\hline hear & heard & hearable & hearken & perceive & learn & steer & heat & bounce & lie \\
\hline herb & herbs & herbal & herbivorous & plant & seasoning & blurb & early & under & over \\
\hline high & higher & highness & highlander & utmost & elation & sigh & hike & silver & metal \\
\hline hole & holes & holey & unholed & opening & fault & role & home & cord & plug \\
\hline hope & hoped & hoper & unhopefulness & desire & promise & elope & home & dive & swim \\
\hline infect & infected & infection & disinfectant & taint & contaminate & respect & infidel & jalapeno & incognito \\
\hline inform & informed & informant & $\begin{array}{l}\text { infor- } \\
\text { mationless }\end{array}$ & $\begin{array}{l}\text { com- } \\
\text { municate }\end{array}$ & testify & storm & enfold & sing & grab \\
\hline inquire & inquired & inquirer & inquisition & ask & wonder & wire & inquiet & toe & nose \\
\hline insist & insisted & insistence & insistingly & implore & assert & leftist & incipient & foghorn & traffic \\
\hline insure & insured & insurance & overinsuring & guarantee & ascertain & allure & instead & chickpea & dodgeball \\
\hline intend & intended & intention & intentionally & plan & plot & offend & intact & language & orange \\
\hline intern & interns & internship & internment & work & imprison & learn & integer & eye & ear \\
\hline
\end{tabular}




\begin{tabular}{|c|c|c|c|c|c|c|c|c|c|}
\hline join & joined & joiner & rejoinder & together & sum & groin & joyful & vulture & weapon \\
\hline jump & jumped & outjump & unjumpable & leap & bound & pump & judge & horsefly & totebag \\
\hline large & larger & largely & enlargement & big & great & barge & lobby & desk & mat \\
\hline laugh & laughed & laughter & laughable & chuckle & giggle & graph & lack & paper & mitten \\
\hline lend & lending & lender & relending & loan & impart & mend & lentils & soccer & police \\
\hline level & levels & levelness & level-headed & aim & even & devil & leaven & yardstick & $\begin{array}{l}\text { spread- } \\
\text { sheet }\end{array}$ \\
\hline light & lights & lighten & enlighten & radiance & ignite & might & lime & bag & dirt \\
\hline list & listed & listing & blacklist & enumerate & recite & twist & lip & maple & hazel \\
\hline live & lives & livable & unlively & inhabit & experience & give & litter & tongue & knee \\
\hline mask & masks & masklike & unmasked & disguise & camouflage & task & mantle & bone & frame \\
\hline master & masters & mastery & masterfully & chief & dominate & blaster & mackerel & noodle & bronco \\
\hline match & matching & matchable & matchmaker & correspond & pair & catch & matter & clueless & bother \\
\hline meter & meters & diameter & metrical & yard & measure & cheater & meaning & example & paragraph \\
\hline miss & missing & amiss & missy & overlook & girl & swiss & mitt & tiger & lantern \\
\hline money & monies & monetary & monetaristic & currency & cash & honey & mother & suit & tie \\
\hline mother & mothers & motherly & motherhood & parent & reproduce & other & mud & comet & fungus \\
\hline move & moved & movement & locomotive & travel & proceed & groove & moon & apron & tracksuit \\
\hline mutate & mutated & mutation & mutable & change & mature & amputate & music & orange & storage \\
\hline name & names & nametag & nomenclature & identity & mention & same & nasal & ghost & fork \\
\hline narrate & narrated & narration & narrative & $\begin{array}{l}\text { commen- } \\
\text { tary }\end{array}$ & tell & aerate & nasal & white & red \\
\hline nation & nations & national & nationality & country & tribes & station & namely & can & cap \\
\hline nurse & nurses & nursing & nursery & heal & breastfeed & purse & neuron & cabbage & carrot \\
\hline opaque & opaqued & opacity & non- & non- & un- & mistake & au-pair & book & fan \\
\hline organize & organized & $\begin{array}{l}\text { orga- } \\
\text { nizable }\end{array}$ & $\begin{array}{l}\text { opaqueness } \\
\text { disorga- } \\
\text { nization }\end{array}$ & $\begin{array}{l}\text { transparent } \\
\text { direct }\end{array}$ & $\begin{array}{l}\text { intelligible } \\
\text { engineer }\end{array}$ & rationalize & oratory & floodlight & techno \\
\hline paste & pasted & pasty & pastiness & stick & glue & haste & pale & tune & pulp \\
\hline peel & peeled & peelable & unpeeled & skin & disrobe & steal & peek & hatchback & birdseed \\
\hline
\end{tabular}

(Appendix. cont.) 
(Cont.)

\begin{tabular}{|c|c|c|c|c|c|c|c|c|c|}
\hline Key: & Inflected & Derived 1 & Derived 2 & Meaning 1 & Meaning 2 & Rhyme & Cohort & Unrelated 1 & $\begin{array}{l}\text { Unrelated } \\
2\end{array}$ \\
\hline permit & permitted & permission & permissible & allow & license & hermit & perfect & cabinet & classicist \\
\hline phonic & phonics & phonetic & telephone & sound & speech & elec-tronic & follow & package & label \\
\hline photo & photos & $\begin{array}{l}\text { photo- } \\
\text { graph }\end{array}$ & photographic & picture & display & Kyoto & phobia & daisy & garlic \\
\hline physical & physicals & physicality & physicians & body & forcible & $\begin{array}{l}\text { para- } \\
\text { disical }\end{array}$ & fibula & mauve & peach \\
\hline place & placed & placeable & placelessly & position & property & race & plain & endanger & crystallize \\
\hline pluck & plucked & plucker & well-plucked & deplume & pick & buck & plunder & shimmy & rattle \\
\hline plug & plugs & pluggable & unplugging & seal & stopper & chug & plump & hood & peach \\
\hline polish & polished & polisher & depolished & shine & finish & abolish & possum & throw & drink \\
\hline portable & portables & portability & deportation & movable & carry & sortable & porky & summer & winter \\
\hline possess & possessed & possessive & possession & have & own & excess & position & yarn & wick \\
\hline power & powers & powerful & powerlessness & strength & ability & shower & pound & tight & loose \\
\hline pray & prayed & prayer & imprecation & worship & beg & may & prance & cough & sneeze \\
\hline press & pressed & pressure & expressway & push & media & mess & preppy & table & sofa \\
\hline profess & professed & professor & professional & claim & contend & confess & protect & sober & solemn \\
\hline progress & progressing & $\begin{array}{l}\text { pro- } \\
\text { gression }\end{array}$ & $\begin{array}{l}\text { pro- } \\
\text { gressiveness }\end{array}$ & advance & develop & impress & proper & bubbles & monkeys \\
\hline promote & promoting & promotion & self-promotion & upgrade & advertize & devote & produce & dairy & gluten \\
\hline pull & pulled & puller & unpullable & displace & puff & wool & put & cord & lime \\
\hline rain & rains & rainy & rainbows & $\begin{array}{l}\text { preci- } \\
\text { pitation }\end{array}$ & pelting & feign & rate & sweater & bedspread \\
\hline receive & received & receiver & reception & & welcome & achieve & recede & square & cube \\
\hline regular & regulars & ragularity & regulation & standard & veritable & angular & remedy & key & comb \\
\hline relate & related & relation & relativity & associate & pertain & create & relay & bread & pear \\
\hline
\end{tabular}




\begin{tabular}{|c|c|c|c|c|c|c|c|c|c|}
\hline require & required & $\begin{array}{l}\text { require- } \\
\text { ment }\end{array}$ & prerequired & need & demand & conspire & request & elves & cows \\
\hline right & rights & rightful & righteousness & entitlement & correct & flight & rhyme & orange & apple \\
\hline run & ran & runner & runaways & jog & streak & fun & rudder & disk & tape \\
\hline rush & rushed & unrushed & rushingly & hurry & hasten & flush & ruckus & butter-scotch & turpentine \\
\hline save & saved & saver & salvation & rescue & economize & behave & same & garden & pitchfork \\
\hline schedule & scheduled & scheduler & reschedule & agenda & orchestrate & uncool & skeptic & rainbow & protein \\
\hline scoop & scooped & scoopful & outscoop & extract & ladle & group & school & bicycle & volcano \\
\hline scrape & scraped & scrap & unscraped & scuff & abrasion & tape & scrag & bull & fjord \\
\hline search & searching & searchable & $\begin{array}{l}\text { unsearch- } \\
\text { ability }\end{array}$ & seek & investigate & lurch & surface & fleece & rat \\
\hline shine & shining & shiner & shinier & sparkle & luster & whine & shy & road & field \\
\hline sign & signs & signify & signature & mark & contract & mine & sight & hammer & pliers \\
\hline simple & simplest & simplify & simplistically & $\begin{array}{l}\text { unpro- } \\
\text { blematic }\end{array}$ & bare & dimple & scissor & lettuce & mango \\
\hline single & singles & singular & singularly & individual & exclusive & shingle & singe & ash & bay \\
\hline size & sizes & sizable & downsized & magnitude & stiffen & rise & cycle & ring & watch \\
\hline skill & skilled & skillless & skillfulness & aptitude & ability & bill & skimp & forks & balls \\
\hline smoke & smoking & smoky & antismoking & fume & smolder & bloke & smote & finger & puddle \\
\hline soil & soils & soilless & sully & dirt & grime & boil & soybean & platter & guitar \\
\hline sound & sounds & soundness & sonata & noise & rational & bound & south & crayons & holsters \\
\hline space & spaces & spacial & spaciousness & room & distance & race & spade & letter & orange \\
\hline sponge & sponges & spongy & spongecake & mooch & clean & plunge & Sputnik & steel & coal \\
\hline stand & stood & stand-by & standoffish & be upright & pedestal & bland & stab & frown & dig \\
\hline stretch & stretching & stretchable & stretchiness & extend & reach & fetch & stress & funky & mousy \\
\hline style & styles & styleless & stylized & design & manufacture & while & stipend & toddler & granite \\
\hline talk & talking & talkative & talking-to & $\begin{array}{l}\text { com- } \\
\text { municate }\end{array}$ & lecture & rock & topple & key & glass \\
\hline tense & tensed & tension & tenseness & strain & time & fence & tender & hair & coach \\
\hline
\end{tabular}

(Appendix. cont.) 
(Cont.)

\begin{tabular}{|c|c|c|c|c|c|c|c|c|c|}
\hline Key: & Inflected & Derived 1 & Derived 2 & Meaning 1 & Meaning 2 & Rhyme & Cohort & Unrelated 1 & $\begin{array}{l}\text { Unrelated } \\
2\end{array}$ \\
\hline terminate & terminated & $\begin{array}{l}\text { exter- } \\
\text { mination }\end{array}$ & interminable & end & fire & germinate & terse & saddle & bible \\
\hline test & tests & testable & untested & trial & prove & best & tepid & trashcans & marbles \\
\hline thank & thanks & rethank & thankfulness & praise & $\begin{array}{l}\text { ac- } \\
\text { knowledge }\end{array}$ & spank & thatch & guru & pretzel \\
\hline think & thought & thinker & $\begin{array}{l}\text { thought- } \\
\text { fulness }\end{array}$ & believe & intend & $\sin \mathrm{k}$ & thimble & fax & float \\
\hline thumb & thumbs & thumbtack & thimble & digit & hitchhike & dumb & thunder & family & unicorn \\
\hline time & times & timely & timelessness & instance & period & time & tidy & energetic & $\begin{array}{l}\text { under- } \\
\text { standing }\end{array}$ \\
\hline touch & touched & touchable & retouch & affect & concern & clutch & tough & mollusk & stingray \\
\hline track & tracks & tracker & trackability & chase & path & black & travel & dragonfly & chemical \\
\hline true & truer & trueness & untruthful & actual & lawful & blue & truant & jeans & shorts \\
\hline turn & turned & turning & turntable & twist & bend & burn & turtle & socks & pants \\
\hline use & used & usage & usefulness & employ & function & views & usual & bottle & jacket \\
\hline wash & washed & washer & unwashable & rinse & laundry & posh & want & funny & yellow \\
\hline whip & whipped & whiplike & overwhipped & flog & lash & $\operatorname{sip}$ & whisk & cart & skull \\
\hline wise & wiser & wiseness & wisdom & omniscient & sassy & prize & wine & coffee & cycle \\
\hline work & working & worker & unworkable & exert & labour & shirk & word & sticker & candle \\
\hline wrap & wrapped & wrapper & unwrappable & envelop & cloak & tap & rack & candy & sparkle \\
\hline write & written & writer & unwriteable & compose & spell & bite & rise & $\operatorname{tin}$ & glue \\
\hline zip & zipped & zipper & zippable & null & hurry & flip & zinfandel & iceberg & kitchen \\
\hline
\end{tabular}


Part B: Novel Words USEd For Model Testing

\begin{tabular}{llllllllll}
\hline \hline Key: & Inflected & Derived 1 & Derived 2 & Meaning 1 & Meaning 2 & Rhyme & Cohort & Unrelated 1 & Unrelated 2 \\
\hline chronic & chronics & synchronic & chronically & long-lasting & habitual & tomic & crawling & portrait & painting \\
dictate & dictated & dictation & dictatorial & order & speak & nictate & different & similar & various \\
gene & genes & genetic & generation & DNA & heredity & mean & jeep & puzzled & central \\
graph & graphs & graphic & photography & chart & character & calf & gram & moose & mouse \\
locate & located & locator & relocation & discover & situate & advocate & lotion & science & magic \\
part & parts & partly & compartment & component & separate & smart & parson & blink & sneeze \\
port & ports & passport & portability & harbour & wine & cavort & porky & carpenter & watch-maker \\
step & steps & quickstep & overstepping & measure & walk & pep & steady & monitor & monacle \\
table & tables & tabulate & tabularize & spreadsheet & postpone & fable & taser & sock & shoe \\
text & texts & textbook & textual & message & passage & flexed & tenth & hard & free \\
voice & voices & vocal & provoking & speech & articulate & choice & voyeur & rug & mat \\
\hline \hline
\end{tabular}

